\title{
Pentek Concrete Scabbling System: Baseline Report; Greenbook (Chapter)
}

Topical Report July 31, 1997

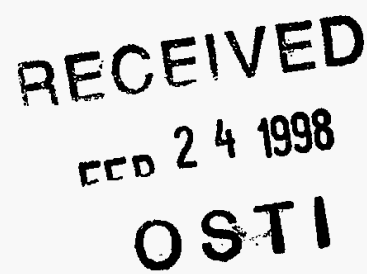

Work Performed Under Contract No.: DE-FC21-95MC32260

For

U.S. Department of Energy

Office of Environmental Management

Office of Technology Development

1000 Independence Avenue

Washington, DC 20585
U.S. Department of Energy

Office of Fossil Energy

Federal Energy Technology Center

Morgantown Site

P.O. Box 880

Morgantown, West Virginia 26507-0880

DETRAUTIOA OF THS DOCUMENT IS UMAMTED
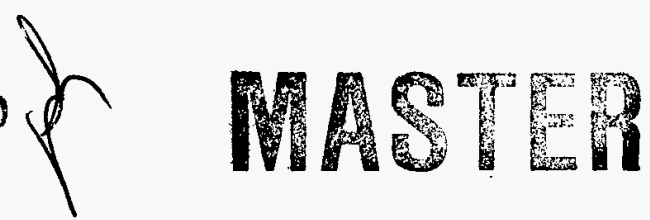
By

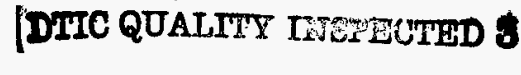

Operating Engineers National Hazmat Program

250 Airport Circle

Beaver, West Virginia 25813 


\section{Disclaimer}

This report was prepared as an account of work sponsored by an agency of the United States Government. Neither the United States Government nor any agency thereof, nor any of their employees, makes any warranty, express or implied, or assumes any legal liability or responsibility for the accuracy, completeness, or usefulness of any information, apparatus, product, or process disclosed, or represents that its use would not infringe privately owned rights. Reference herein to any specific commercial product, process, or service by trade name, trademark, manufacturer, or otherwise does not necessarily constitute or imply its endorsement, recommendation, or favoring by the United States Government or any agency thereof. The views and opinions of authors expressed herein do not necessarily state or reflect those of the United States Government or any agency thereof. 


\section{LTC VACUUM BLASTING - CONCRETE}

\section{TABLE OF CONTENTS}

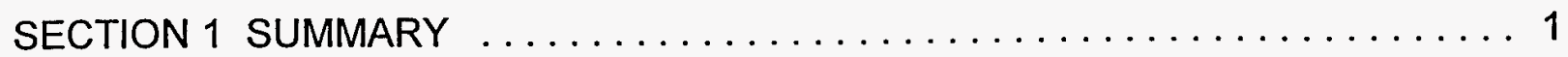

Technology Description ........................... 1

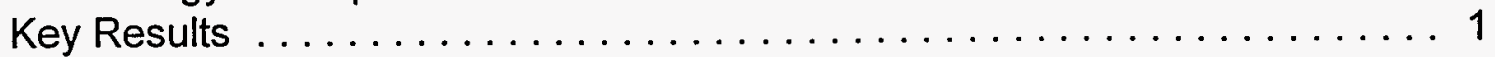

SECTION 2 -TECHNOLOGY DESCRIPTION $\ldots \ldots \ldots \ldots \ldots \ldots \ldots \ldots \ldots \ldots \ldots$

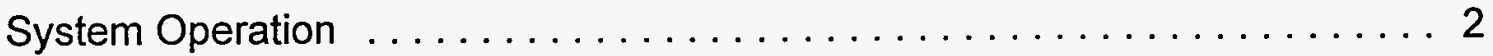

SECTION 3 - HEALTH AND SAFETY EVALUATION $\ldots \ldots \ldots \ldots \ldots \ldots \ldots$

General Health and Safety Concerns $\ldots \ldots \ldots \ldots \ldots \ldots \ldots \ldots \ldots$

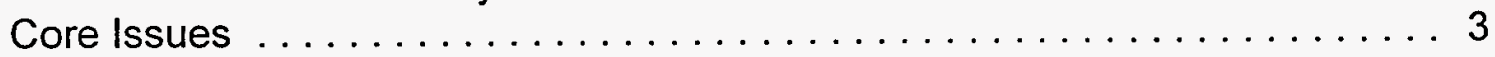

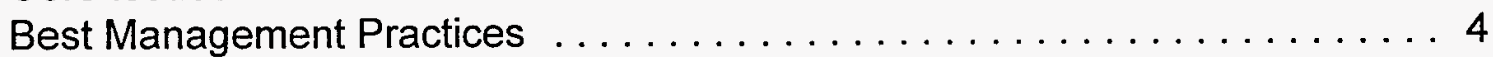

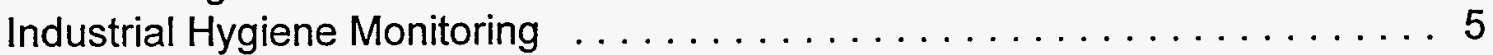

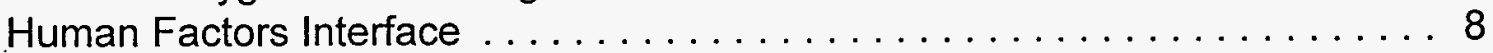

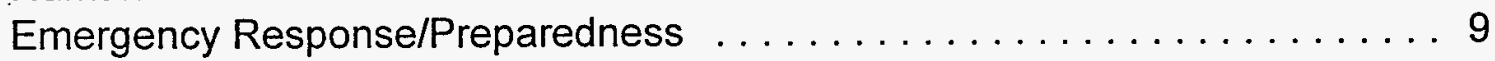

SECTION 4 - TECHNOLOGY APPLICABILITY $\ldots \ldots \ldots \ldots \ldots \ldots \ldots$

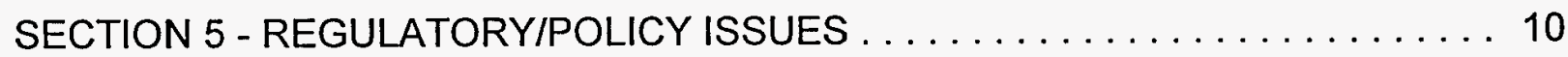

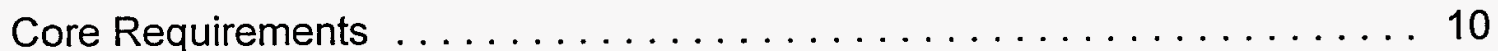

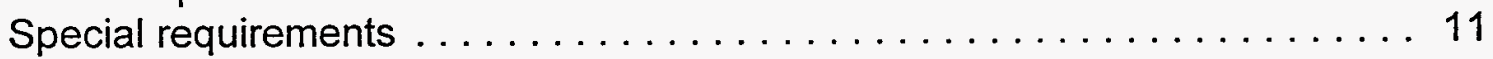

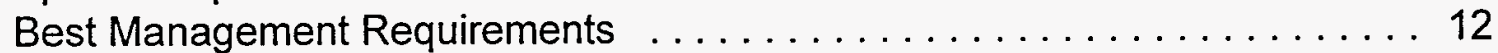

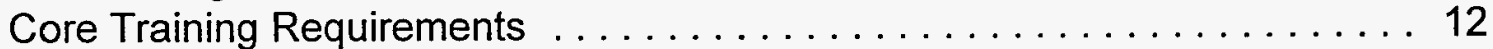

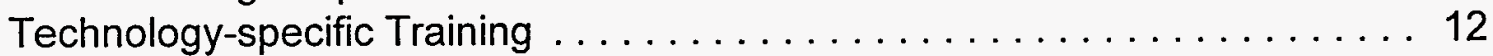

Special Training . . . . . . . . . . . . . . . 13

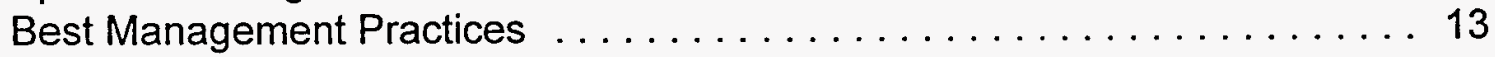

SECTION 6 - OPERATIONAL CONSIDERATIONS AND

RECOMMENDATIONS ...................... 13

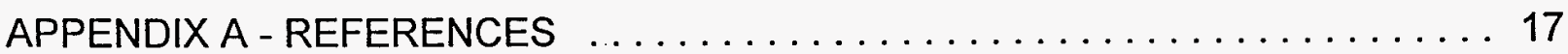

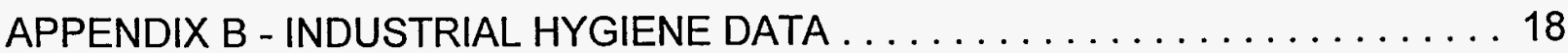




\section{PENTEK SCABBLING \\ (MOOSE ${ }^{\circledR}$, SOUIRREL ${ }^{\circledR}{ }^{\text {I, SOUIRREL }}{ }^{\circledR}$ III) \\ HUMAN FACTORS ASSESSMENT}

\section{SECTION 1 - SUMMARY}

\section{TECHNOLOGY DESCRIPTION}

The Pentek scabbling technology was tested at Florida International University (FIU) and is being evaluated as a baseline technology. This report evaluates it for safety and health issues. It is a commercially available technology and has been used for various projects at locations throughout the country.

The Pentek concrete scabbling system consisted of the MOOSE ${ }^{\circledR}$, SQUIRREL $^{\circledR}-1$, and SQUIRREL ${ }^{\otimes}$-III scabblers. The scabblers are designed to scarify concrete floors and slabs using cross-section, tungsten carbide tipped bits. The bits are designed to remove concrete in $3 / 8$ inch increments. The bits are either 9-tooth or demolition type. The scabblers are used with a vacuum system designed to collect and filter the concrete dust and contamination that is removed from the surface.

\section{KEY RESULTS}

The safety and health evaluation conducted during the testing demonstration focused on two main areas of exposure: dust and noise. Dust exposure was minimal, but noise exposure was significant. Further testing for each of these exposures is recommended. Because of the outdoor environment where the testing demonstration took place, results may be inaccurate. It is feasible that the dust and noise levels will be higher in an enclosed operating environment. Other areas of concern were arm-hand vibration, whole-body vibration, ergonomics, heat stress, tripping hazards, electrical hazards, machine guarding, and lockout/tagout. 


\section{SECTION 2 \\ TECHNOLOGY DESCRIPTION}

\section{SYSTEM OPERATION}

The Pentek scabbling technology was tested at Florida International University (FIU) and is being evaluated as a baseline technology. In conjunction with FIU's evaluation of efficiency and cost, this report covers the human factors assessment conducted for safety and health issues. It is a commercially available technology and has been used for various projects at locations throughout the country.

The MOOSE ${ }^{\circledR}$ is a remotely operated scabbler designed to scarify large concrete floors and slabs. It utilizes a single-step floor scarification process with integral vacuum control with capture at the cutting tool surface. The MOOSE ${ }^{\circledR}$ removes coatings and

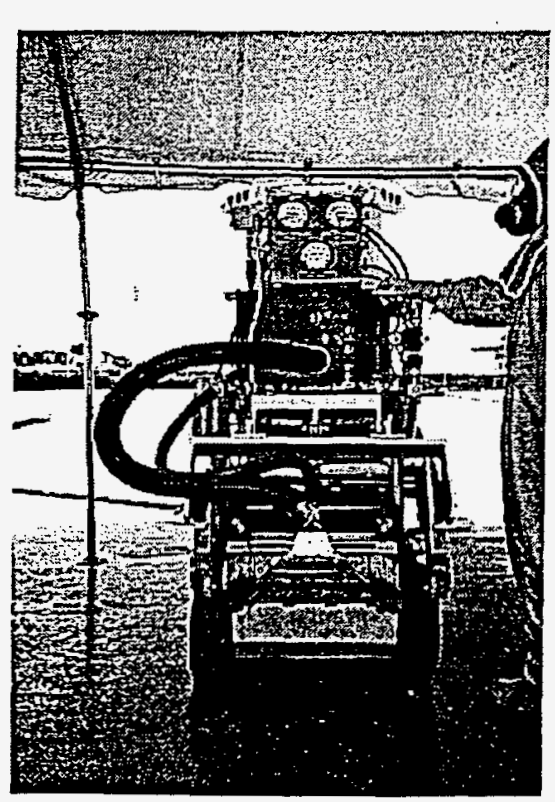

Figure 1 - Pentek MOOSE ${ }^{\oplus}$ concrete substrate in increments of $1 / 16$ inch. Three subsystems comprise the MOOSE ${ }^{\circledR}$ scabbler: the scabbling head assembly, the on-board high efficiency particulate air filter (HEPA) vacuum system, and the six-wheeled chassis. The scabbling head houses seven independent reciprocating tungsten carbide-tipped bits. The bits pulverize the surface by delivering 1200 hammer impacts per minute through pistons driven by compressed air. Dust and debris are captured by the two-stage positive filtration HEPA vacuum system that deposits the waste directly into an on-board 23-gallon waste drum. The first stage filters have a $99.5 \%$ efficiency at 1 micron and a second stage HEPA efficiency of $99.97 \%$ at 0.3 microns. The first stage filters or roughing filters are continuously and automatically cleaned by reverse-flow pulses of high pressure air. The system also has a full-drum alarm. The six-wheeled chassis is powered by dual DC motors. Independent skid steering allows 360 degrees pirouetting around its geometric center.

The SQUIRREL ${ }^{\circledR}$-III is a manually operated pneumatic scabbler designed to scarify concrete floors and slabs. It uses high-speed, reciprocating tungsten carbide tipped pistons to pulverized protective coatings and concrete substrate. Dust and debris are captured by the same vacuum system as described above.

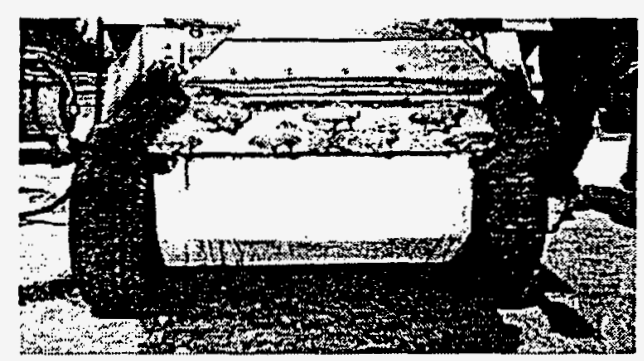

Figure 2 - Tungsten carbide tips on scabbling head of MOOSE ${ }^{\circledR}$ 
SQUIRREL ${ }^{\circledR}-1$ is a manually operated, hand-held scabbler similar in function to the SQUIRREL ${ }^{\circledR}$-III described above.

The operator did not encounter any difficulties with equipment operation while dressed out in the appropriate PPE. The technology did present a significant noise hazard. These as well as other safety and health factors will be discussed in greater detail in other sections of this report.

The scabblers left some water on the concrete pad during operation. In an environment with alpha-contaminated concrete, this could create a secondary contamination. This seemed to be caused by water in the air lines. Routine preventive maintenance must be an intrinsic part of the process to prevent this type of secondary contamination created by the technology itself. The heat exchanger on the air compressor must be in the "on" position to avoid this problem.

\section{SECTION 3 \\ HEALTH AND SAFETY EVALUATION}

\section{GENERAL SAFETY AND HEALTH CONCERNS}

Personnel where the Pentek scabbling technology is being used need to be concerned with safety and health issues. Issues that personnel need to be cognizant of may be divided into two categories. Core issues are those that are based on current safety and health regulatory requirements. Best management practices are related to issues that are not based on current safety and health regulations but are key elements in preventing worker injury and illness on the job.

Safety and health issues of concern with the Pentek scabbling technology included:

\section{Core Issues:}

- Tripping hazards - the electric cords, air lines, and vacuum hoses needed to operate the equipment are tripping hazards. The need for stringent housekeeping must be evaluated.

- Pinch points - the potential exists for the operator to have his/her fingers/hand crushed during operation if the hand is placed in the area of the horizontal cylinder on the scabbling head. The scabbling head design needs to be evaluated for machine guarding at this location or at least the hazard needs to be labeled with the appropriate warning. Scabbling mode should never be activated while maintenance is being conducted on the scabbling head. This will be considered under a lockout/tagout program. 
- Electrical hazards - the generator and electric cords necessary to operate the equipment can present electrical hazards. The need for ground fault circuit interrupters, grounding, and strain relief must be evaluated.

- Lockout/Tagout - the user of the technology will need to develop a lockout/tagout program to assure there is not an accidental release of energy during maintenance/repair activities.

- Noise - the user was subjected to a significant amount of noise while operating the MOOSE ${ }^{\circledast}$, SQUIRREL ${ }^{\circledR}-1$, and SQUIRREL ${ }^{\circledR}$-III scabblers used during the testing demonstration. Noise exposure will be discussed in greater detail in a later section of this report.

- Dust - the equipment did not generate visible dust during operation, but larger debris was left on the scabbled surface at the sides of the scabbling head. The amount of dust generated in the breathing zone of the operator may change based on the environment in which the concrete decontamination is taking place. Therefore, the user of the technology will need to develop a sampling plan based on the individual site needs. It should also be noted that there is potential for contamination from exposure to dust when changing filters and when changing out a debris collection drum.

When a diesel engine is used to operate ancillary equipment such as the air compressor, exposure to diesel fumes must also be taken into consideration.

- Compressed gas hazard - when power for the MOOSE ${ }^{\circledR}$ is not available for unloading, compressed nitrogen may be used. During the testing demonstration, nitrogen was used but had to be hand-carried while walking the MOOSE ${ }^{\circledR}$ off of the truck. A hook for the bottle located on the MOOSE ${ }^{\circledR}$ would eliminate the chance of dropping it. Rupture of the bottle could result in serious injury.

\section{Best management practices:}

- Heat stress - the operator was subjected to an increase in heat stress due to the need to utilize Anti-C PPE. The user will need to develop a heat stress program for the environment in which the technology is being used, taking into consideration any PPE that may need to be utilized.

- Ergonomics - the user was subjected to some ergonomic stressors such as, stooping, bending, twisting, kneeling, and lifting. Of particular concern is the need to manually lift the full drum used to collect dust. The drum may weigh 220 
pounds or more. A mechanical method such as a hand operated lift needs to be utilized.

- Arm-hand vibration - the user was subjected to arm-hand vibration while operating the SQUIRREL ${ }^{\circledR}-1$ and SQUIRREL ${ }^{\circledR}$-III scabblers, but not during the operation of the MOOSE ${ }^{\circledR}$. Whole-body vibration was a concern during MOOSE operation due to shaking of the concrete surface that was being scabbled. The ability of the MOOSE ${ }^{\circledR}$ to cause vibration to the surface being scabbled needs to be considered on a job-by-job basis.

- Struck by hazards - the air lines have the potential to cause severe injury if a fitting were to fail. The Chicago fittings had safety pins; however, a safety line between the male and female end of the fittings would prohibit the line from becoming airborne.

- Communication - due to the noise generated by the technology during operation, communication can be difficult. Personnel working in the area should be knowledgeable in and proficient in the use of hand signals.

\section{Industrial Hygiene Monitoring}

During the current testing demonstration with the Pentek scabbling system, sampling was conducted for dust and noise. The wet-bulb globe temperature was monitored to evaluate heat stress. Observational evaluation was conducted for ergonomics, and arm-hand vibration.

Through general observational techniques the potential for ergonomic problems was evaluated during the testing demonstration. There is potential for muscle/back stress and/or injuries due to bending, twisting, and lifting associated with setup, operation, maintenance, and decontamination. There is potential for stress and/or injury to the knees due to the kneeling and stooping required during setup, operation, maintenance, and decontamination activities. The potential for back and knee stress was most evident during operation of the SQUIRREL ${ }^{\otimes}-1$, since it is a hand-operated tool, and the operator must either bend, stoop, or kneel during use.

During the testing demonstration arm-hand vibration exposure was present during the operation of SQUIRREL ${ }^{\circledR}$-I and SQUIRREL ${ }^{\circledR}$-III. While arm-hand vibration was not quantitatively measured, it was readily apparent that there was exposure to arm-hand vibration that could potentially cause conditions such as Raynaud's syndrome. In addition, when the handle of SQUIRREL ${ }^{-}$- III was placed against the leg or pelvic area of the operator, this part of the body was exposed to vibration. 
Heat stress was monitored using a Quest QuestTemp ${ }^{\circ} 15$ Heat Stress Monitor. The wet-bulb globe temperature was used to determine the work/rest regimen in accordance with the American Conference of Governmental Industrial Hygienist (ACGIH) recommendations. The wet-bulb globe temperature was adjusted for the type of clothing, including PPE, that the worker was wearing.

The worker's blood pressure, pulse, and temperature were monitored throughout the day. No problems were encountered due to heat stress, but the worker's comfort level was decreased when wearing the Anti-C PPE. While heat stress will be increased while wearing PPE, the overall heat stress response will vary from worker to worker. Each situation in which the technology is used should be evaluated for the heat stress potential, taking into consideration the wet-bulb globe temperature, PPE in use, physical condition of the worker, and the amount of worker acclimatization.

Dust monitoring was conducted with a sampling train consisting of an SKC IOM Inhalable dust sampler coupled with a MSA Escort Elf air sampling pump. Pre- and post-sampling calibration was accomplished using a BIOS International DryCal DC1 primary calibration system. Sampling filters were desiccated pre- and post-sampling and weighed on a Denver Instrument Company A-200DS scale. Sampling was conducted in accordance with $\mathrm{NIOSH}$ method 0500.

Personal sampling was conducted on the equipment operators during scabbling operations. Personal dust sampling results of $0.0 \mathrm{mg} / \mathrm{m}^{3}$ and $0.0 \mathrm{mg} / \mathrm{m}^{3}$ were obtained for Operator Number 1 and results of $2.0083 \mathrm{mg} / \mathrm{m}^{3}$ and $0.0 \mathrm{mg} / \mathrm{m}^{3}$ were obtained for Operator Number 2. These values do not exceed the Occupational Safety and Health Administration (OSHA) permissible exposure limit (PEL) or the ACGIH threshold limit value (TLV) of $15 \mathrm{mg} / \mathrm{m}^{3}$ and $10 \mathrm{mg} / \mathrm{m}^{3}$ respectively for total dust. Larger pieces of debris were left on the scabbled surface at the sides of the scabbling head. These could potentially become an airborne inhalation hazard. It is recommended that additional sampling be conducted in an enclosed environment. A complete air sampling plan for a site would need to be developed to include not only dust but other contaminants specific to the concrete decontamination project. (See Appendix B for sampling data.)

Personal noise monitoring was conducted using Metrosonic $\mathrm{db}-3100$ data logging noise dosimeters. Calibration was conducted pre- and post-monitoring using a Metrosonic CL304 acoustical calibrator. Monitoring was conducted on Operator Number 1 for 1.5 hours (90 minutes) and again for 4.78 hours (287 minutes) during operation of the scabbling system. Monitoring during this time showed a noise dose of $100.35 \%$, which gives an 8-hour time-weighted average (TWA) of $90.0 \mathrm{dBA}$ and $164 \%$, which gives an 8 -hour TWA of $93.5 \mathrm{dBA}$. If Operator Number 1 continued to have the same level of noise exposure during the 8-hour shift a projected 8-hour TWA would produce a noise 
dose of $532.56 \%$, or an 8-hour TWA of $102.1 \mathrm{dBA}$ and $489.27 \%$, or an 8-hour TWA of $101.5 \mathrm{dBA}$.

Monitoring on Operator Number 2 was conducted for 1.5 hours (90 minutes) and again for 2.85 hours ( 171 minutes) during operation of the scabbling system. Monitoring showed a noise dose of $94.72 \%$, which gives an 8 -hour TWA of $89.6 \mathrm{dbA}$ and $174.75 \%$, which gives an 8-hour TWA of $94 \mathrm{dBA}$. If Operator Number 2 continued to have the same level of noise exposure during the 8-hour shift a projected 8-hour TWA would produce a noise dose of $504.77 \%$, or an 8-hour TWA of $101.7 \mathrm{dBA}$ and a noise dose of $519.38 \%$, or an 8-hour TWA of $101.9 \mathrm{dBA}$ respectively.

Monitoring showed a noise dose of $94.72 \%$, which gives an 8-hour TWA of 89.6 dBA and $174.75 \%$, which gives an 8 -hour TWA of $94 \mathrm{dBA}$. If Operator Number 2 continued to have the same level of noise exposure during the 8-hour shift a projected 8-hour TWA would produce a noise dose of $504.77 \%$, or an 8-hour TWA of $101.7 \mathrm{dBA}$ and a noise dose of $519.38 \%$, or an 8 -hour TWA of $101.9 \%$ dBA.

The OSHA allowable PEL for noise is a $100 \%$ dose or an 8 -hour TWA of $90 \mathrm{dBA}$. Operator Number 1 was not overexposed after 1.5 hours of operation, but was overexposed after 4.78 hours of operation (assuming the operator had no other noise exposure during the work shift). Operator Number 2 was not overexposed after 1.5 hours of operation, but was overexposed after 2.85 hours of operation (assuming the operator had no other noise exposure during the work shift). At these exposure levels, personnel would be required to be included in a hearing conservation program.

Feasible engineering controls, administrative controls, and personal protective equipment (PPE-hearing protection devices) need to be used. The percentage of time spent at each noise level (for the two most significant exposures) that comprise the exposures can be seen in Appendix B. For Operator Number 1, 1.577\% of the time the noise exposure was less than $85 \mathrm{dBA}$ which means that the majority of the time or $98.42 \%$ of the time the noise exposure was at sound levels above $85 \mathrm{dBA}$. For the Operator Number $2,1.566 \%$ of the time the noise exposure was less than $85 \mathrm{dBA}$ which means that the majority of the time or $98.43 \%$ of the time the noise exposure was at sound levels above $85 \mathrm{dBA}$. OSHA requires that a hearing conservation program be initiated if the 8-hour TWA is $85 \mathrm{dBA}$.

During the 4.78 hours of operation for Operator Number 1, the noise levels were averaged for each one minute period of time and then an overall average of each one minute period was calculated and gave an average exposure level of 101.4 dBA for an $80 \mathrm{~dB}$ cutoff Level And $101.4 \mathrm{dBA}$ for a $90 \mathrm{~dB}$ cutoff level for the 4.78 hours of operation and $102.0 \mathrm{dBA}$ for an $80 \mathrm{~dB}$ and $90 \mathrm{~dB}$ cutoff Level And for the 1.5 hours of operation. The average exposure level for Operator Number 2 was $101.9 \mathrm{dBA}$ for an $80 \mathrm{~dB}$ cutoff Level And $101.8 \mathrm{dBA}$ for a $90 \mathrm{db}$ cutoff level for the 2.85 hours of operation and 101.7 $\mathrm{dBA}$ for an $80 \mathrm{~dB}$ and $90 \mathrm{db}$ cutoff level for a $90 \mathrm{db}$ cutoff level for the 1.5 hours of 
operation. OSHA requires an $80 \mathrm{~dB}$ cutoff for hearing conservation measurements and a $90 \mathrm{db}$ cutoff for engineering controls compliance measurements. The maximum sound level observed during the measurement period was $113.0 \mathrm{dBA}$ and $113.9 \mathrm{dBA}$ for Operator Number 1 and $108.7 \mathrm{dBA}$ and $111.2 \mathrm{dBA}$ for Operator Number 2 . The highest instantaneous sound pressure level was $132.0 \mathrm{~dB}$ and $135.1 \mathrm{~dB}$ for Operator Number 1 and $134.3 \mathrm{~dB}$ and $129.3 \mathrm{~dB}$ for Operator Number 2.

These measurements define noise as a significant exposure for personnel operating the Pentek scabbling system using MOOSE ${ }^{\circledR}$, SQUIRREL ${ }^{\circledR}$-I, and SQUIRREL ${ }^{\circledR}$-III. It must also be noted that the equipment was being operated in an open outdoor environment at the time of the measurements and operation in an enclosed facility would have the potential to increase the noise level due to other influences such as vibration and reverberation. Therefore, it is recommended that noise monitoring be conducted while the equipment is being operated in an enclosed environment.

\section{HUMAN FACTORS INTERFACE}

The technologies being tested for concrete decontamination and decommissioning are targeted for alpha contaminated concrete, therefore, the equipment operators were dressed-out in Anti-C (alpha radiation) PPE which included cloth suit, hood, inner and outer boots, inner and outer gloves, and full face air-purifying respirator. Due to the full face respirator, the operators had some visibility problems while operating the equipment when wearing the Anti-C PPE. There was also a decrease in dexterity due to the gloves. This caused some problems during roughing filter change out. The need to perform work in the Anti-C PPE caused some increase in heat stress for the operator.

If the concrete being decontaminated had contamination other than or in addition to alpha radiation, additional levels of protection, such as Level A or Level B PPE, may be required for the operator. These may create additional human interface problems such as a greater decrease in visibility and manual dexterity, an increase in heat stress, and an overall increase in physical stress. It is recommended that additional safety and health evaluations be conducted utilizing these higher levels of protection.

Additional human factors interface issues concerned the control panel and gauges located on the MOOSE ${ }^{\circledR}$ itself. These items include the adjustability of the operating station, full tank light, and control gauges. These will be discussed with recommendations for improvement in section 6 of this report. 


\section{EMERGENCY RESPONSE/PREPAREDNESS}

The use of the Pentek concrete scabbling technology would not be applicable to emergency response.

Emergency response/preparedness must be part of every hazardous waste site safety and health plan. In addition to credible site emergencies, site personnel must plan for credible emergencies in connection with the MOOSE ${ }^{\oplus}, \mathrm{SQUIRREL}^{\circledR}-\mathrm{I}$, and SQUIRREL ${ }^{\oplus}$-III.

All precautions used when responding to an emergency situation at the site will apply. Before entering an area where the MOOSE ${ }^{\circledR}$, SQUIRREL $^{\circledR}$-I, and SQUIRREL ${ }^{\circledR}$-III are being used, the equipment needs to be completely shut down (de-energized).

This technology does not appear to present any conditions that would lead to out of the ordinary emergencies.

\section{SECTION 4 TECHNOLOGY APPLICABILITY}

Te technology did deposit some visible dust into the atmosphere. Air monitoring did not show dust level above the PPE. However, this was difficult to assess due to the windy outdoor testing environment. There were larger pieces of debris left on the surface at the sides of the scabbling head. The system needs to be evaluated to determine if an increase in vacuum air flow would help with this problem.

The MOOSE ${ }^{\oplus}$, SQUIRREL ${ }^{\circledR}$-I, and SQUIRREL ${ }^{\circledR}$-III will need to be torn down to be decontaminated. This will not necessarily guarantee that decontamination for alpha will be complete and it will be difficult to survey for alpha contamination due to all of the small hard to reach (with a probe) spaces inherent in the equipment.

According to the technology representative, many parts, such as the hoses and brushes, may be considered consumables. In addition, the roughing filters can be removed directly into a bag and disposed of, thereby helping to eliminate additional worker exposure to contamination. 


\section{SECTION 5 \\ REGULATORYIPOLICY ISSUES}

The site safety and health personnel where the Pentek concrete scabbling technology is being used need to be concerned with safety and health regulations applicable to the issues discussed above. Regulations that apply may be divided into four categories. Core requirements are those regulations that would apply to any hazardous waste work site, regardless of the type of job. Technology specific requirements are those regulations that apply due to the specific technology being used. Special requirements are standards and policies that are specific to the technology itself and are required by reference in a regulation. Best management practices are not required but are recommended by organizations such as the American National Standards Institute (ANSI), the National Institute of Occupational Health and Safety (NIOSH), Department of Energy (DOE), National Fire Protection Association (NFPA), etc. These regulations/standards may include but not be limited to the following:

\section{Core requirements:}

- OSHA 29 CFR 1926.25 Housekeeping

- OSHA 29 CFR 1910.141 Sanitation (1910.141(a)(3) covers housekeeping)

- OSHA 29 CFR 1926.53 lonizing Radiation

- OSHA 29 CFR 1910.96 lonizing Radiation

- OSHA 29 CFR 1926 Subpart Z Toxic and Hazardous Substances

- OSHA 29 CFR 1910 Subpart Z Toxic and Hazardous Substances

- OSHA 29 CFR 1926.59 Hazard Communication

- OSHA 29 CFR 1910.1200 Hazard Communication

- OSHA 29 CFR 1926.64 Process Safety Management of Highly Hazardous Chemicals

- OSHA 29 CFR 1910.119 Process Safety Management of Highly Hazardous Chemicals 
OSHA 29 CFR 1926.65 Hazardous Waste Operations and Emergency Response

OSHA 29 CFR 1910.120 Hazardous Waste Operations and Emergency Response

Occupational Safety and Health Act 1970(5)(a)(1) General Duty Clause

Technology specific requirements:

- OSHA 29 CFR 1926 Subpart K Electrical

- OSHA 29 CFR 1910 Subpart S Electrical

- OSHA 29 CFR 1926 Subpart I Tools-Hand and Power

- OSHA 29 CFR 1910 Subpart P Hand and Portable Powered Tools and Other Hand-Held Equipment

- OSHA 29 CFR 1910 Subpart O Machinery and Machine Guarding

- OSHA 29 CFR 1910.147 The Control of Hazardous Energy (Lockout/Tagout)

- OSHA 29 CFR 1926.52 Occupational Noise Exposure

- OSHA 29 CFR 1910.95 Occupational Noise Exposure

- OSHA 29 CFR 1926.103 Respiratory Protection

OSHA 29 CFR 1910.134 Respiratory Protection

OSHA 29 CFR 1926.102 Eye and Face Protection

- OSHA 29 CFR 1910.133 Eye and Face Protection

- OSHA 29 CFR 1926.28 Personal Protective Equipment

- OSHA 29 CFR 1910.132 General Requirements (Personal Protective Equipment)

- OSHA 29 CFR 1926.23 First Aid and Medical Attention

OSHA 29 CFR 1910.151 Medical Services and First Aid 
- ACGIH Threshold Limit Values for Chemical Substances and Physical Agents and Biological Exposure Indices

\section{Best Management Practices:}

- ANSI S3.34-1986 Guide for the Measurement and Evaluation of Human Exposure to Vibration Transmitted to the Hand

ANSI S3.18-1979 Guide for the Evaluation of Human Exposure to Whole-body Vibration

In addition to the above regulations and policies, it is imperative that all workers have appropriate and adequate training for the task and associated safety and health conditions. Training that would be required may be divided into four categories. Core training is that which is required for anyone entering a hazardous waste site to perform work, regardless of the type of job. Technology specific training is that training that is specific to the technology and required by safety and health standards. Special training is that which is specific to the technology to assure the worker is adequately trained for the task but is not necessarily required by safety and health standards. Best management practices are trainings that while not mandated by health and safety standards, provide information and knowledge to the worker that will allow the worker to perform his/her job safely. Training to be applied for the Pentek scabbling system may include but not be limited to:

\section{Core training requirements:}

- HAZWOPER (Hazardous Waste Operations and Emergency Response)

- HAZCOM (Hazard Communication)

Radiation Safety (Radiation Worker Training) for radiation sites

Technology Specific Training:

- Respiratory Protection

- Hearing Conservation

- Personal Protective Equipment

- Electrical Safety 
Lockout/Tagout

Special training:

- Job specific training for equipment operation

\section{Best Management Practice training:}

- Ergonomics (proper lifting, bending, stooping, kneeling, arm-hand vibration, whole-body vibration)

- Heat stress (learning to recognize signs and symptoms)

- CPR/First Aid/Emergency Response/Blood-borne Pathogens

- Hand Signal Communication

- Construction Safety (OSHA 500) and or General Industry Safety (OSHA 501)

\section{SECTION 6 OPERATIONAL CONSIDERATIONS \& RECOMMENDATIONS}

- Workers must be aware of the tripping hazards associated with hoses and cords that are necessary to operate the equipment. Keeping these as orderly as possible in compliance with good housekeeping regulations will help avoid injury due to tripping. In addition, the operators had to find somewhere to place tools that were being used during operations. A specific place for tools located on the operating station would improve housekeeping in this area.

- The vacuum hoses were not connected to the outlet on the pieces of equipment by means of a clamping system, and at times were duct taped. This could allow the hoses to be pulled loose and create an exposure to the contaminant. Hoses should be attached with some type of clamping system to reduce the possibility that they will become detached accidentally.

- The operators of the equipment need to have training in ergonomics to assure proper techniques in lifting, bending, stooping, twisting, etc. during equipment operation. The hand operated unit (SQUIRREL ${ }^{\oplus}$ ) should be evaluated for the possibility of attaching a handle that would allow the worker to operate it from a 
standing position, thereby eliminating the need to stoop, sit, and/or kneel. This would also eliminate the additional exposure to contaminants the worker receives due to the need to contact the contaminated surface.

- The operator was not required to have control of the MOOSE ${ }^{\circledR}$ at all times in order to keep it running. The operator was able to leave the operating station and walk in front of or behind the scabbler. This could lead to a struck by, contacted by, or caught between accident. Standard Operating Procedures (SOP's) need to be developed that require the operator to stay with the control panel at all times or the use of a "dead-man" switch on the control panel needs to be considered. Additionally, the equipment design needs to be evaluated for the possibility of placing sensors on the MOOSE $₫$ that would cause a shut-down if objects were too close during operation.

- Water from the air lines was dripping onto the concrete surface. This causes a secondary contamination as well as a slipping hazard. It should be assured that the heat exchanger on the air compressor is in the "on" position to avoid this problem.

- The Chicago fittings had safety pins but if the fitting and the pin failed, a flying hose has the potential to cause severe injury. A safety line connected to the male and female ends of the fitting would keep the hose from becoming airborne.

The control panel for the MOOSE ${ }^{\circledR}$ was located on a wheeled cart. The panel needs to be permanently attached to the cart to avoid accidentally knocking it off the cart. The cart needs to be vertically adjustable to allow operators of different heights to adjust the station for comfort and correct posture while operating the scabbler.

- The power line from the control panel to the scabbler was often in the way and had to frequently be moved, which caused the operator to walk away from the control panel. A system on the operating station cart that automatically allowed the cord to retract and/or swivel would be beneficial to the operator.

The auditory alarm on the control panel that indicated the drum was full was often not heard due to the noisy operating environment. An alarm such as a vibration of the control panel would be more noticeable to the operator and therefore avoid an overfill of the drum.

- The control gauges located on the MOOSE ${ }^{\circledR}$ itself such as the rough filter gauge were often difficult to see from a distance. A duplication of these gauges on the operating station would enable the operator to react to them in a more timely 
manner. Additionally, some of the numerical ranges for the needle gauges were not adequate. For example, on the rough filter gauge, the range was $0-5$. The needle pegged often but there was no indication of the degree of problem after the needle passed the 5 mark. It is suggested that the range be made wider and color coded for better visibility and redundancy.

- When changing-out a full drum the operator must use the hand controls on the MOOSE ${ }^{\oplus}$. They are difficult to reach (the operator is stooping and must reach above shoulder and head height) and they are used blindly since the operator cannot look at the gauges and the drum/drum seal at the same time. Moving the controls to a position where they are easily accessible and visible to the operator during drum change is recommended.

- There is an E-stop located on the control panel but not on the MOOSE ${ }^{\circledR}$ itself. The tether person may notice a potential problem before the operator but may not be able to communicate to him/her quickly. It is recommended that there be an E-stop located on the MOOSE ${ }^{\circledR}$ for the tether person to use, if necessary. Additionally, a warning signal (visual/auditory) should be incorporated to indicate activation of the E-stop.

- A full drum may weigh 220 pounds or more. This presents great potential for back injury when two operators lift the drum for change out. It is recommended that the system be evaluated for use with a mechanical lifting system.

- During rough filter changing, the filters are changed directly into a plastic bag and disposed of. The operator had some difficulty with tactile sensation working with gloves and bag at the same time. It is recommended that glove bags be considered for use. This would allow the operator greater dexterity and still provide for containing the contamination during disposal. In addition the bag was held in place by duct tape. It is recommended that some type of hooks be used to hold the bag in place instead.

\section{- When changing out a full drum, a cardboard disk is used as a barrier between} the drum and filter unit. This disk is held in place by the vacuum suction. If there was a loss in vacuum pressure during change out the disk will fall and there is an increase in the potential for exposure to the contaminant. It is recommended that a system such as hooks be designed to hold the disk in place in the event that vacuum pressure would be lost.

It was also noted that at times, the drum tended to fill unevenly. This caused difficulty in placing the lid on the drum before change out and it increased the potential for worker exposure to the contaminants. It is recommended that the 
design be evaluated for the use of something such as a vibratory hammer that would pack the dust down into the drum more evenly.

- The horizontal cylinders on the scabbling head of the MOOSE ${ }^{\circledR}$ present the potential for crushing injuries. The design needs to be evaluated for guarding this area. At a minimum, there should be a written warning on the scabbler.

- To set the frequency of cleaning (blow back) on the roughing filters, the operator had to open the front panel of the MOOSE ${ }^{\circledR}$. This would cause contamination to the inside of the panel. It is recommended that a mechanism that allows this adjustment to be made be placed on the outside of the panel.

- Noise exposure was significant during operation of the technology. Since testing was done in an outdoor environment, it is plausible that the noise levels would increase in an enclosed environment. The equipment needs to be evaluated for possible engineering controls to help decrease the noise exposure to the operator. If engineering controls are not possible, administrative controls, and/or adequate hearing protection must be incorporated during operation.

Due to the windy outdoor environment in which the testing demonstration was conducted, it is recommended that further testing for dust exposure and noise exposure be conducted while the technology is used in an enclosed environment similar to environments in which it would be used at a hazardous waste clean-up site. This would also allow for a more thorough evaluation of the heat stress to be encountered while wearing the appropriate PPE.

It is also recommended that the operation and maintenance activities be evaluated while the operator is wearing Level $A$ and Level B PPE since these levels may be needed in environments where the concrete contamination is mixed in nature or other than radiation.

The safety and health issues discussed throughout this report could be reduced, and in some cases eliminated, if this type of scabbling technology could be operated remotely from a location outside the contaminated environment. 


\section{Appendix A \\ REFERENCES}

Occupational Safety and Health Standards for General Industry, 29 CFR Part 1910, Occupational Safety and Health Administration United States Department of Labor, 1995

Occupational Safety and Health Standards for the Construction Industry, 29 CFR Part 1926, Occupational Safety and Health Administration United States Department of Labor, 1995

Threshold Limit Values(TLV's) for Chemical Substances and Physical Agents and Biological Exposure Indices (BEl's), American Conference of Governmental Industrial Hygienists, 1995-1996

ANSI 1986, Guide for the measurement and evaluation of human exposure to vibration transmitted to the hand, New York, NY: American National Standards Institute, ANSI S3.34 
Appendix B

IH SAMPLING DATA

\begin{tabular}{|c|c|c|c|}
\hline \multicolumn{4}{|c|}{ 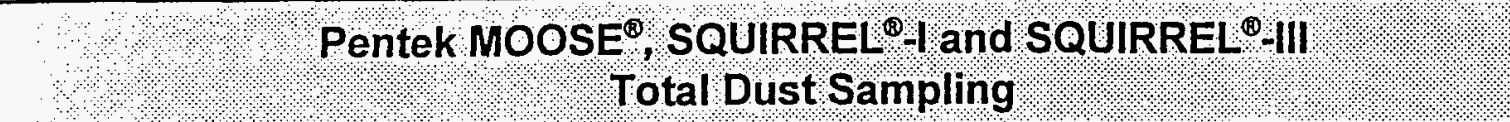 } \\
\hline Dato & Sample Minnoer & Anallo & Fersuls \\
\hline $5 / 7 / 79$ & 050796-FIU-005 & Total dust & $0.0000 \mathrm{mg} / \mathrm{m}^{3}$ \\
\hline $5 / 7 / 96$ & 050796-FIU-006 & Total dust & $2.0083 \mathrm{mg} / \mathrm{m}^{3}$ \\
\hline $5 / 7 / 96$ & 050796-FIU-007 & Blank & $0.0000 \mathrm{mg} / \mathrm{m}^{3}$ \\
\hline $5 / 7 / 96$ & 050796-FIU-008 & Total dust & $0.0000 \mathrm{mg} / \mathrm{m}^{3}$ \\
\hline $5 / 7 / 96$ & 050796-FIU-009 & Total dust & $0.0000 \mathrm{mg} / \mathrm{m}^{3}$ \\
\hline
\end{tabular}

* The OSHA PEL for total dust is $15 \mathrm{mg} / \mathrm{m}^{3}$ and the ACGIH TLV is $10 \mathrm{mg} / \mathrm{m} 3$. Current sampling was conducted for total dust. The need to sample for respirable dust and silica has to be considered during concrete decontamination and decommissioning activities. 


\section{NOISE SAMPLING}

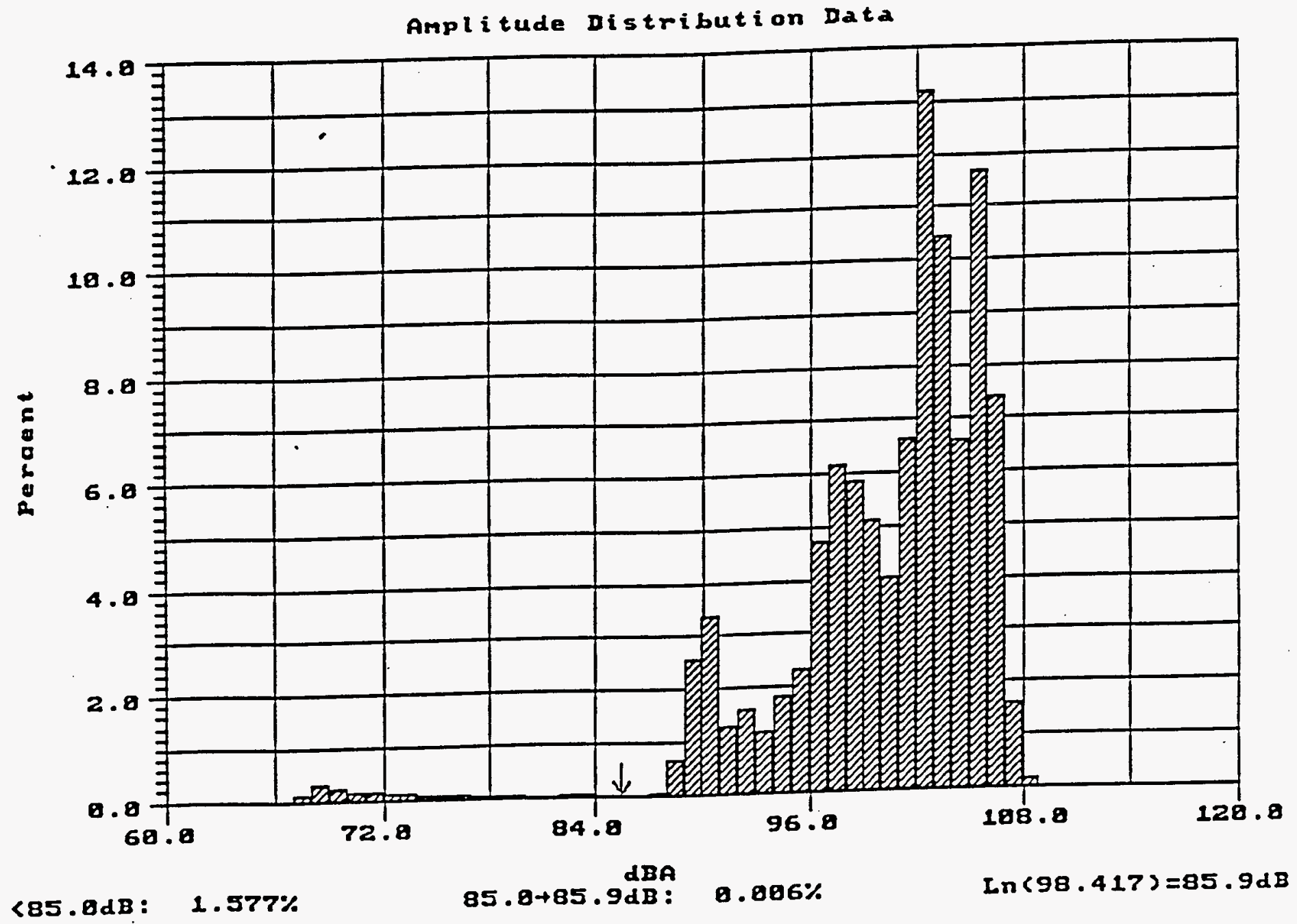

The percentage of time spent at each decibel level can be obtained from the graph. As shown, $1.577 \%$ of the time the noise exposure was less than $85 \mathrm{dBA}$ which means that the majority of the time or $98.42 \%$ of the time the noise exposure was at sound levels above $85 \mathrm{dBA}$. OSHA requires that a hearing conservation program be initiated if the 8-hour TWA is $85 \mathrm{dBA}$. 


\section{NOISE SAMPLING}

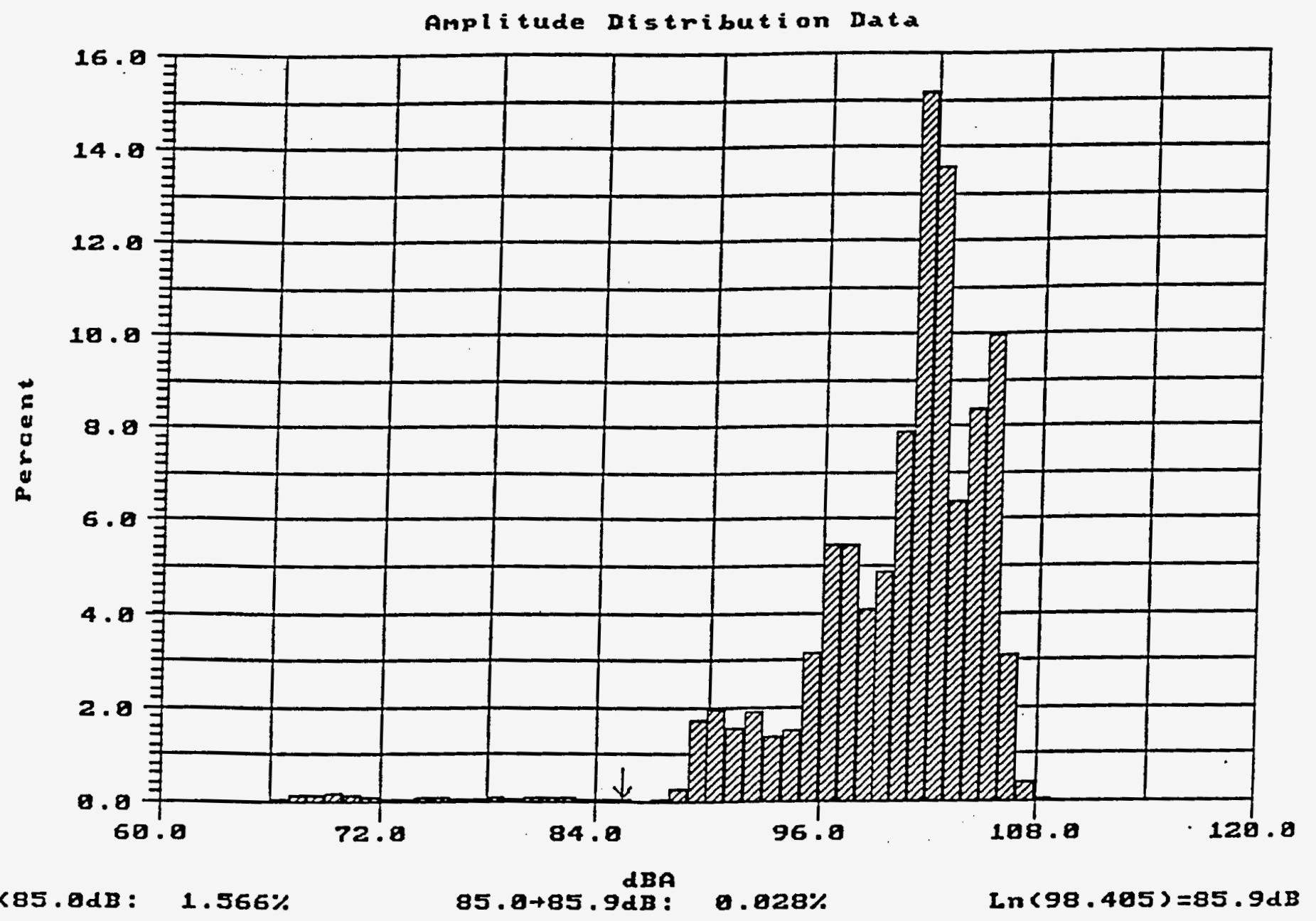

The percentage of time spent at each decibel level can be obtained from the graph. As shown, $1.566 \%$ of the time the noise exposure was less than $85 \mathrm{dBA}$ which means that the majority of the time or $98.43 \%$ of the time the noise exposure was at sound levels above $85 \mathrm{dBA}$. OSHA requires that a hearing conservation program be initiated if the 8-hour TWA is $85 \mathrm{dBA}$. 
Report Number (14) Do $/ \mathrm{mC} / 32260--5844$
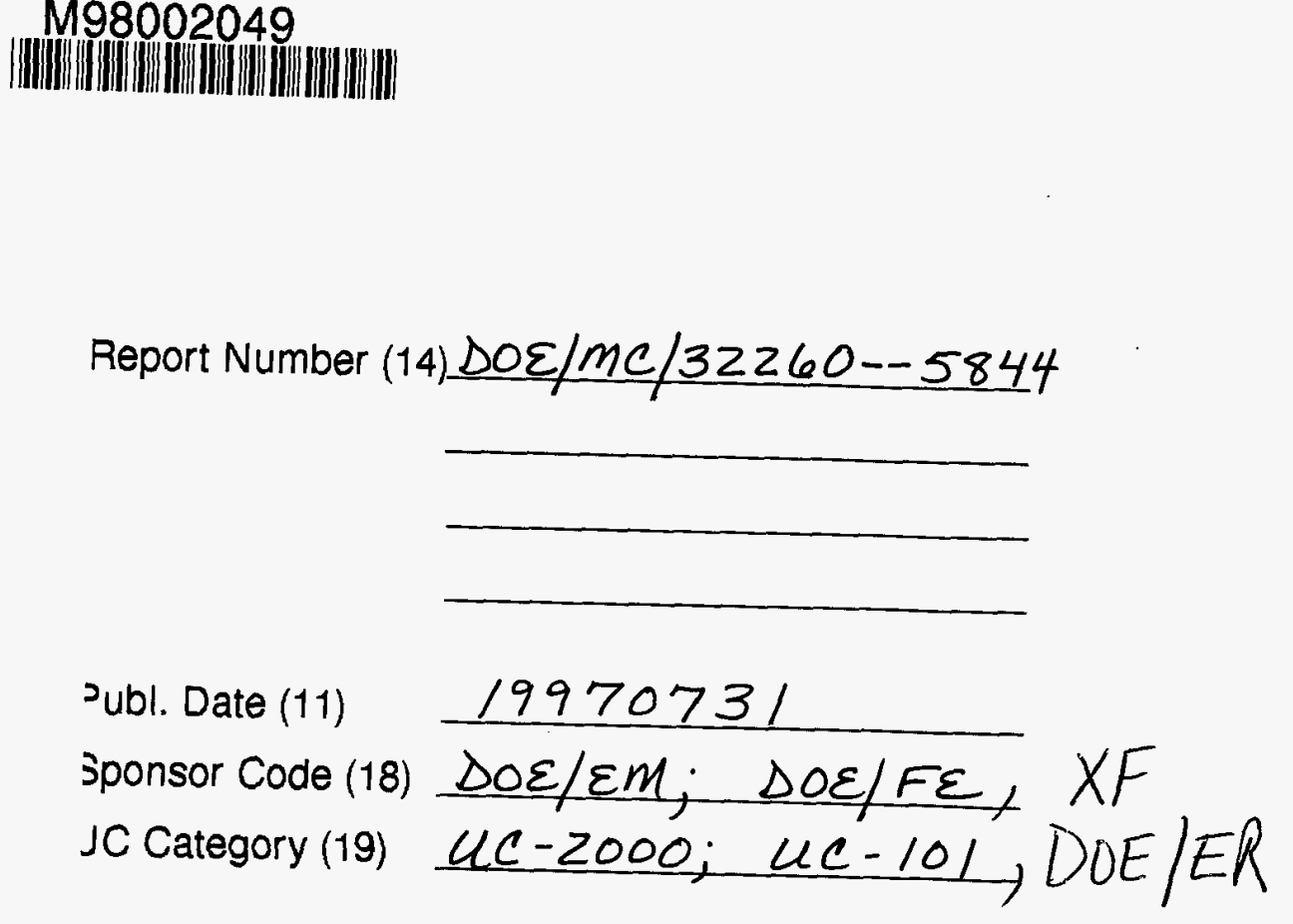